\title{
ACRITARCOS (GRUPO ACRITARCHA EVITT 1963): CONCEITOS GERAIS, APLICAÇÕES E IMPORTÂNCIA NA ANÁLISE ESTRATIGRÁFICA DO INTERVALO PENNSILVANIANO E PERMIANO DA BACIA DO PARANÁ
}

\author{
Cristina Moreira FÉLIX \\ Paulo Alves de SOUZA
}

\begin{abstract}
RESUMO
Embora constituam palinomorfos de natureza biológica incerta, os acritarcos são comumente utilizados para fins bioestratigráficos e de interpretação paleoambiental, principalmente para os depósitos de idade entre o Cambriano e o Devoniano. Este trabalho apresenta uma revisão atualizada sobre os aspectos morfológicos, classificação, distribuição estratigráfica e aplicações dos microfósseis de parede orgânica alocados neste grupo no âmbito das Geociências. Registros brasileiros são exemplificados, principalmente de bacias intracratônicas paleozoicas, com destaque para os depósitos pennsilvanianos e permianos da Bacia do Paraná. Como principais resultados obtidos para este intervalo na bacia, destacam-se: (i) muitos dos táxons identificados como acritarcos possivelmente têm parentesco com algas prasinofíceas e zignematáceas e (ii) a constatação de intervalos com associações abundantes em espécimes atribuídos aos gêneros Micrhystridium e Veryhachium, corroborando interpretações prévias sobre um marco estratigráfico permiano de natureza marinha, incluindo depósitos da porção superior da Formação Palermo à porção mais inferior da Formação Irati. A revisão taxonômica revela um período de declínio acentuado da diversidade de espécies (blackout fitoplanctônico) para o Carbonífero e Permiano em nível mundial, principalmente considerando a riqueza em nível genérico, muito menor que aquela observada para os depósitos pré-carboníferos no Brasil e em outras partes do mundo.
\end{abstract}

Palavras-chave: palinologia, Paleozóico Superior, fitoplâncton, Bacia do Paraná, Gondwana.

\section{ABSTRACT}

Despite their uncertain biological affinity, the palynomorphs known as acritarchs are commonly used for biostratigraphic and paleoenvironmental interpretation, particularly of Cambrian to Devonian deposits. This paper presents an updated review of the morphology, classification and stratigraphic distribution of organicwalled microfossils included in this group, as well as their application in Geosciences. Brazilian records from Paleozoic intracratonic basins, especially from Pennsylvanian and Permian deposits of the Paraná Basin, are discussed. The main results of the analysis of this interval in the basin are (i) many of the taxa identified as acritarchs are related to species of prasinophyceae and zygnemataceae algae, and (ii) the record of intervals with abundant association of specimens assigned to the genera Micrhystridium and Veryhachium, which corroborates previous interpretations of a Permian stratigraphic marker of marine nature at the top of the Palermo Formation and base of the Irati Formation. The taxonomic review supports the idea of a worldwide decrease in diversity of these taxa during the Pennsylvanian and Permian interval (phytoplankton blackout), especially considering richness at the generic level, which was much lower than that observed in pre-Carboniferous deposits in Brazil and in other parts of the world.

Keywords: Palynology, Late Paleozoic, phytoplankton, Paraná Basin, Gondwana. 


\section{INTRODUÇÃO}

Numa concepção moderna, a paleopalinologia compreende o estudo da matéria orgânica microscópica que persiste após a dissolução e eliminação dos componentes inorgânicos de um sedimento ou rocha sedimentar (TRAVERSE 2008). O resíduo orgânico é constituído por três grupos: (i) palinomorfos, que incluem esporomorfos (esporos de briófitas e pteridófitas, grãos de pólen de gimnospermas e angiospermas), cistos de dinoflagelados e outros elementos algálicos (clorofíceas), acritarcos, escolecodontes, algumas estruturas de fungos (esporos e hifas) e, quitinozoários; (ii) fitoclastos, referentes a restos de material vegetal, tais como cutículas e microfragmentos de lenhos e (iii) matéria orgânica amorfa, composta pelos registros de matéria degradada, ou semidegradada.

Dentre os palinomorfos, táxons atribuídos ao Grupo Acritarcha EVITT 1963 e a algas da Divisão Chlorophyta são muito utilizados para fins bioestratigráficos e de interpretação paleoambiental. O termo "Acritarcha" foi introduzido por EVITT (1963) para reunir palinomorfos distintos dos esporomorfos ou quitinozoários, com afinidade biológica desconhecida. Compreende vesículas, ornamentadas ou não, de dimensões reduzidas, correspondentes, provavelmente, a cistos do fitoplâncton de depósitos marinhos e continentais. Do ponto de vista da sistemática biológica, equivalem a elementos incertae sedis reunidos em um agrupamento artificial, com classificação exclusivamente baseada em caracteres morfológicos.

Diversos gêneros foram instituídos e incluídos no Grupo Acritarcha, principalmente pela ausência de análogos modernos, dificultando uma atribuição sistemática mais próxima da classificação biológica atual. Por outro lado, estudos mais aprofundados têm demonstrado que alguns gêneros correspondem a determinados grupos de algas (MONTENARI \& LEPPIG 2003, RIEGEL 2008). Assim, diversos táxons foram realocados para ordens e classes das divisões Chlorophyta e Pyrrophyta, além de suspeitas de que certos táxons podem estar relacionados a esporos de fungos. Dessa forma, constata-se que as classificações do grupo têm caráter efêmero e estão sujeitas a mudanças e, por outro lado, há dificuldades no estabelecimento de padrões diagnósticos que evidenciem o significado biológico de cada táxon. De maneira geral, os 13 subgrupos instituídos por DOWNIE et al. (1963) para o Grupo Acritarcha abarcam a grande parcela de variação morfológica destes cistos, representados por dezenas de gêneros e centenas de espécies (SARJEANT \& STANCLIFFE 1994), cuja maior diversidade foi registrada entre o Cambriano e o Devoniano.

De acordo com vários autores, durante o Carbonífero e o Permiano, ocorreu uma drástica diminuição da diversidade de espécies denominada "blackout" do fitoplâncton (WINSLOW 1962, WICANDER 1975, MOLYNEUX et al. 1984, VANGUESTAINE 1986, LE HÉRISSÉ et al. 2000, FILIPIAK 2005, RIEGEL 2008), no qual a maioria dos gêneros comuns até o Devoniano extinguem-se. Contudo, há outros indicativos de que a diversidade e a abundância do grupo não foram fortemente afetadas (LEI et al. 2012), o que torna a ideia do "blackout" passível de discussões.

A grande variedade morfológica dos acritarcos, o tamanho reduzido e, em muitos casos, sua má preservação são algumas das dificuldades para a sua análise. Além disso, alguns espécimes só são visíveis sob luz fluorescente, enquanto a microscopia eletrônica de varredura é bastante eficaz na análise taxonômica. Entretanto, estas duas técnicas nem sempre são viáveis em trabalhos de rotina.

Uma profunda revisão taxonômica foi realizada por FÉLIX (2012) para os palinomorfos distintos dos esporomorfos que ocorrem no intervalo entre o Pennsilvaniano e o Permiano da Bacia do Paraná no Brasil. Como resultado, foram propostas novas concepções sobre a classificação sistemática dos táxons atribuídos ao Grupo Acritarcha e às algas prasinofíceas e clorofíceas, tendo como base critérios de natureza morfológica, associados a análises ontogenética, estratigráfica e tafonômica.

O objetivo deste trabalho é apresentar uma revisão sobre o estado de conhecimento do Grupo Acritarcha EVITT 1963, abordando aspectos morfológicos da classificação sistemática, bem como o significado paleoecológico, paleoambiental, bioestratigráfico, paleoclimático e paleogeográfico, complementando, assim, a contribuição de CRUZ (2011). Exemplos de utilização desses fósseis são apresentados, com destaque para ocorrências brasileiras, principalmente aqueles oriundos das bacias intracratônicas paleozoicas, especialmente dos depósitos pennsilvanianos e permianos da Bacia do Paraná.

\section{CONSIDERAÇÕES GERAIS}

\subsection{Generalidades e aspectos morfológicos}

O termo "acritarco(s)" é o aportuguesamento do substantivo relativo aos organismos que constituem a categoria sistemática "Grupo Acritarcha" EVITT 1963, também mencionado como "acritarca(s)" por diversos autores na literatura 
brasileira. Acritarcos são protistas unicelulares, constituídos por cistos de parede orgânica, considerados como o grupo mais antigo de organismos marinhos com organização celular eucariótica (MONTENARI \& LEPPIG 2003). O termo foi cunhado por William Evittem 1963 (do grego akritos $=$ incerto, arche $=$ origem), correspondendo a um grupo fitoplanctônico, morfologicamente variado e de provável origem polifilética. Sua similaridade com as algas modernas, seja pela ultraestrutura da parede com alta resistência, ou pelos diferentes meios de excistamento (abertura do cisto para liberação do conteúdo), levou vários autores a considerar os acritarcos como representantes fósseis do estágio de cisto do ciclo de vida das algas.

Os cistos consistem de uma cavidade central simples ou de múltiplas camadas (vesícula oca), podendo comportar processos, membranas em forma de septos ou alas, além de simetria, forma, estrutura e ornamentação variadas. A parede dos cistos fósseis é de composição orgânica, fechada ou com comunicação com o exterior. A forma do corpo pode ser esférica, fusiforme, estrelada ou prismática. Os processos podem ser simples ou complexos, sólidos ou ocos.

As estruturas de abertura simples podem ser divididas em dois grupos: suturas lineares, que variam em posição e forma, e pilomas (pequenos orifícios circulares na vesícula). Essas últimas características e a distribuição estratigráfica em nível mundial são fortemente sugestivas de um organismo parecido com dinoflagelados (STROTHER 1996).

De acordo com LE HERISSÉ (1989), os critérios taxonômicos utilizados na distinção genérica incluem caracteres morfológicos internos e externos como a forma da vesícula e simetria, o tipo e o modo de distribuição de ornamentos na superfície da vesícula, relações com ornamentos da vesícula, ou seja, a presença ou ausência de comunicação com a cavidade central, a estrutura de parede e o modo de abertura. A abertura nos acritarcos aparece como uma estrutura complexa, mas, para o autor citado acima, não pode ser usada como o principal critério de diferenciação genérica.

Já para SARJEANT \& STANCLIFFE (1994), os principais critérios utilizados são o número de espinhos ou processos, sua natureza, se são sólidos ou ocos, e, nesse último caso, se as suas cavidades estão ou não ligadas ao interior da vesícula.

Outro importante aspecto do estudo da morfologia do grupo é o arranjo geométrico ou topologia dos elementos componentes, que destaca a posição dos processos e a ornamentação da vesícula, bem como as camadas que constituem as paredes. Os cistos são muito variáveis em tamanho, podendo atingir, de acordo com CRUZ (2011) de 5 a $150 \mu \mathrm{m}$.

A ultraestrutura e a composição da parede dos acritarcos são importantes na análise taxonômica. Para STROTHER (1996), a ultraestrutura da parede dos acritarcos pode refletir diferenças taxonômicas importantes. Contudo, sua análise requer o uso de equipamentos tais como, o microscópio eletrônico de transmissão, ainda não largamente disponíveis para trabalhos de rotina. A parede é constituída de material semelhante à esporopolenina (a forma estrutural como ela se apresenta é muito diversa nos diferentes palinomorfos), composta de politerpenos (MARTIN 1993). A análise química da estrutura da parede também seria caráter diagnóstico; esta técnica requer uma quantidade mínima de espécimes da mesma espécie por amostra.

De acordo com STROTHER (1996), o grupo representa o registro fóssil da base da cadeia alimentar global durante o Proterozoico e o Paleozoico e, juntamente com as cianobactérias, são importantes para o entendimento sobre a evolução dos organismos autótrofos (produtores de oxigênio), e, por sua vez, sobre a composição da atmosfera terrestre.

\subsection{Classificação sistemática}

Em termos sistemáticos, os acritarcos, assim como as algas, são subordinados ao Código Internacional de Nomenclatura Botânica. É geralmente aceito que correspondam a cistos do fitoplâncton marinho e, por isso, representam apenas uma etapa de um ciclo de vida.

Antes da criação do termo "Acritarco" em 1963, utilizava-se a denominação "hystrichosphaerídeos" (WETZEL 1933), divisão que incluía os dinoflagelados e outras formas de origem incerta. EVITT (1963) propôs que o termo "hystrichosphaera" deveria ser restrito aos dinoflagelados, enquanto o termo "acritarch" poderia ser utilizado para microfósseis com corpo semelhante àquelas formas, mas que não pudessem ser identificados como tal.

$\mathrm{Na}$ tentativa de organizar a situação taxonômica vigente em 1961, quando alguns autores usavam a classificação zoológica para o grupo (e.g. WETZEL 1933) e outros a botânica (e.g., DEFLANDRE 1947), DOWNIE et al. (1961) propuseram que os fósseis de dinoflagelados e os hystrichosphaerídeos (sensu latu, incluindo acritarcos), fossem classificados de acordo com o Código Internacional de Nomenclatura Botânica. Em 1963, EVITT propôs que os acritarcos fossem designados como "Grupo", termo que expressa o conceito de associação de formas similares sem afinidades bio- 
lógicas comuns. DOWNIE et al. (1963) sugeriram o uso da divisão deste grupo em subgrupos, tendo como base feições morfológicas características. Os subgrupos propostos são ilustrados na figura 1 , e brevemente descritos e exemplificados na tabela 1 .

Embora ainda sujeito a controvérsias, esse arranjo parataxonômico é o mais utilizado atualmente. Contudo, dos subgrupos listados por DOWNIE et al. (1963), alguns tiveram gêneros removidos para as algas da Divisão Chlorophyta, Classe Prasinophyceae (vide TAPPAN 1980, p. 818-820 e GUY-OHLSON 1996, p. 182), tais como Cymatiosphaera WETZEL 1933 ex DEFLANDRE 1954 e Dictyotidium EISENACK emend. STAPLIN 1961, pertencentes ao subgrupo Herkomorphitae; gêneros do subgrupo Pteromorphitae, como Pterospermella EISENACK 1972 e Tasmanites (NEWTON 1875) SCHOPF, WILSON \& BENTALL 1944 e, gêneros do subgrupo Sphaeromorphitae, como Leiosphaeridia EISENACK 1958. Essas reinterpretações taxonômicas corroboram as ideias de BOALCH \& PARKE (1971), que identificaram diferentes morfologias relacionadas a distintos estágios de vida dos gêneros holocênicos Halosphaera, Pachysphaera e Pterosperma (Prasinophyceae), comparando-os ao gênero fóssil Tasmanites. Maiores informações sobre as implicações taxonômicas vinculadas a esses táxons de clorofíceas são objeto de trabalho conseguinte, em desenvolvimento pelos autores do presente trabalho.

O subgrupo Sphaeromorphitae reúne espécimes com morfologias muito simples, porém difíceis de classificar e agrupar, como vesículas esféricas e sem ornamentação, às vezes reunidas em aglomerados. Embora as formas do gênero Leiosphaeridia tenham sido realocadas para as algas prasinofíceas, o subgrupo Sphaeromorphitae é muito comum no registro geológico, sendo composto por outras formas esféricas distintas deste gênero.

LOEBLICH Jr. (1970) sugeriu a organização dos gêneros e espécies de acritarcos em ordem alfabética. Por outro lado, alguns autores, tais como DOWNIE (1973), tentaram agrupar as espécies segundo as semelhanças entre os gêneros, o que possivelmente refletiria origens e relações filogenéticas. Como exemplo, cita-se o grupo informal "Micrhystridium - Veryhachium", que por sua vez, também foi tratado como "complexos" morfológicos distintos por SARJEANT \& STANCLIFFE (1994). Estes últimos autores listaram várias diagnoses e emendas

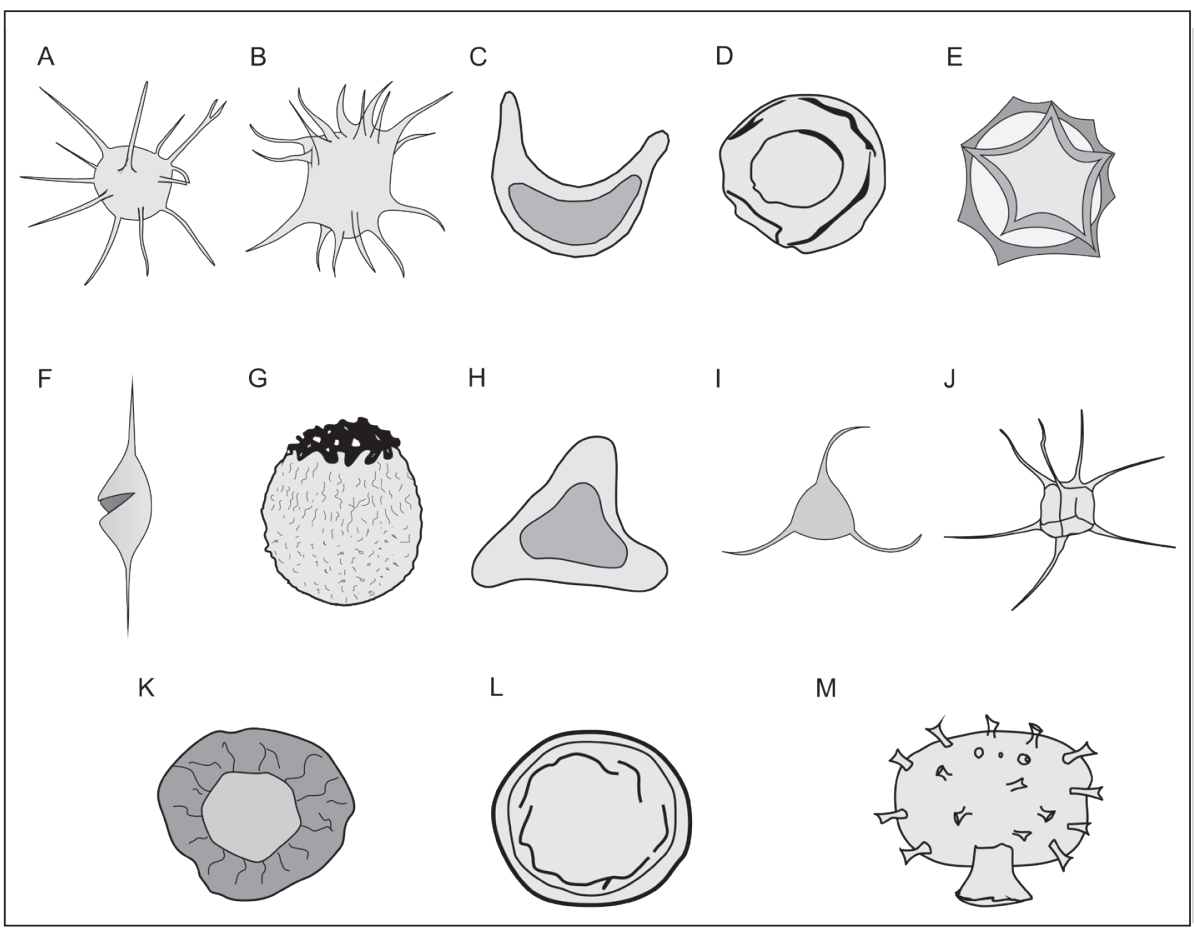

FIGURA 1 - Ilustrações de alguns dos gêneros representativos dos subgrupos de acritarcos (DOWNIE et al. 1963): A. Acanthomorphitae; B. Diacromorphitae; C. Dinetromorphitae; D. Disphaeromorphitae; E. Herkomorphitae, F. Netromorphitae; G. Oomorphitae; H. Platymorphitae; I. Polygonomorphitae; J. Prismatomorphitae, K. Pteromorphitae; L. Sphaeromorphitae; M. Stephanomorphitae (modificado de PEREIRA 2004). 
TABELA 1 - Subgrupos de acritarcos (DOWNIE et al. 1963), com descrição sumária e exemplos de gêneros compreendidos.

\begin{tabular}{|c|c|}
\hline Subgrupo & Descrição \\
\hline $\begin{array}{l}\text { A. Acanthomorphitae } \\
\text { (Akantha: espinho) }\end{array}$ & $\begin{array}{l}\text { Compreendem acritarcos de forma esférica a subesférica, processos isolados, sim- } \\
\text { ples ou ramificados, sólidos ou vazios, distribuídos regular ou irregularmente e } \\
\text { possuindo piloma simples. Ex.: Micrhystridium, Baltisphaeridium }\end{array}$ \\
\hline $\begin{array}{l}\text { B. Diacromorphitae } \\
\text { (di-Akron: dois pólos) }\end{array}$ & $\begin{array}{l}\text { Acritarcos de vesícula elipsoidal a esférica. A zona equatorial apresenta-se lisa ou } \\
\text { ligeiramente enrugada; as zonas polares ornamentadas com pontos, tubérculos ou } \\
\text { espinhos. Não se observam aberturas. Ex.: Acanthodiacrodium, Dasydiacrodium }\end{array}$ \\
\hline $\begin{array}{l}\text { C. Dinetromorphitae } \\
\text { (di-netron: dois fusos) }\end{array}$ & $\begin{array}{l}\text { Acritarcos de corpo fusiforme a alongado, algumas vezes amplamente curvados, } \\
\text { contendo corpo interno, esférico a elipsoidal. Geralmente sem cristas ou proces- } \\
\text { sos, ou com processos simples fechados distalmente. Aberturas, quando presentes, } \\
\text { são em forma de piloma circular simples, em posição polar. Ex.: Diplofusa }\end{array}$ \\
\hline $\begin{array}{l}\text { D. Disphaeromorphita e } \\
\text { (di-Sphaira: duas esferas) }\end{array}$ & $\begin{array}{l}\text { Acritarcos esféricos a ovóides, com um corpo central interno. Superfície da vesí- } \\
\text { cula e do corpo interno, lisa ou granular. Sem cristas ou processos, sem abertura } \\
\text { ou com piloma simples circular. Ex.: Disphaeria, Archaeosacculina }\end{array}$ \\
\hline $\begin{array}{l}\text { E. Herkomorphitae } \\
\text { (Herkos: muros) }\end{array}$ & $\begin{array}{l}\text { Acritarcos de corpo esférico a elipsoidal ou subpoligonal. Superfície subdividida } \\
\text { por cristas, em campos poligonais de forma regular ou irregular, lisa, pontuada ou } \\
\text { tuberculada. Aberturas de excistamento, quando presentes, são pilomas simples } \\
\text { ou circulares. Ex.: Cymatiogalea }\end{array}$ \\
\hline $\begin{array}{l}\text { F. Netromorphitae } \\
\text { (Netron: fuso) }\end{array}$ & $\begin{array}{l}\text { Acritarcos de forma alongada, fusiforme. Superfície lisa, raramente granular, } \\
\text { com um ou mais espinhos, fechados distalmente e posicionados nos pólos. Ex.: } \\
\text { Deunffia, Leiofusa, Domasia }\end{array}$ \\
\hline $\begin{array}{l}\text { G. Oomorphitae } \\
\text { (Oon: ovo) }\end{array}$ & $\begin{array}{l}\text { Acritarcos de corpo esférico a elipsoidal, com superfície lisa ou granulosa, um } \\
\text { pólo ornamentado. Ex.: Ooidium }\end{array}$ \\
\hline $\begin{array}{l}\text { H. Platymorphitae } \\
\text { (Platys: plano) }\end{array}$ & $\begin{array}{l}\text { Acritarcos com uma vesícula planar, de contorno circular, oval ou triangular, com } \\
\text { um corpo interno de forma similar, sem cristas ou processos. Superfície lisa a } \\
\text { granular, sem aberturas. Ex.: Halophoridia, Platycystidia }\end{array}$ \\
\hline $\begin{array}{l}\text { I. Polygonomorphitae } \\
\text { (Poly-gonia: muitos ângulos) }\end{array}$ & $\begin{array}{l}\text { Acritarcos de contorno poligonal. Poucos processos isolados, ou fusionados na } \\
\text { base, geralmente simples e raramente ramificados. Ex.: Veryhachium }\end{array}$ \\
\hline $\begin{array}{l}\text { J. Prismatomorphitae } \\
\text { (Prisma: prisma) }\end{array}$ & $\begin{array}{l}\text { Acritarcos de forma geral poligonal a prismática, com extremidades mais ou me- } \\
\text { nos pontiagudas, frequentemente resultando em uma borda, geralmente inteira ou } \\
\text { denteada. Superfície lisa, granular ou reticulada. Não é observada nenhuma aber- } \\
\text { tura nas paredes. Ex.: Polyedrixium }\end{array}$ \\
\hline $\begin{array}{l}\text { K. Pteromorphitae } \\
\text { (Ptero: alas) }\end{array}$ & $\begin{array}{l}\text { Acritarcos esféricos a elipsoidais, ou poligonais. Franja equatorial suportada por } \\
\text { pilares ou dobras radiais. Não se observam outros processos ou cristas. Superfície } \\
\text { lisa ou granular. Ex.: Duvernaysphaera }\end{array}$ \\
\hline $\begin{array}{l}\text { L. Sphaeromorphitae } \\
\text { (Sphaira: esfera) }\end{array}$ & $\begin{array}{l}\text { Acritarcos com a morfologia geral esférica a elipsoidal. Superfície granular, lisa, } \\
\text { pontuada ou perfurada, sem processos, cristas ou abas. Possui abertura do tipo } \\
\text { piloma circular simples ou rompimento da parede. }\end{array}$ \\
\hline $\begin{array}{l}\text { M. Stephanomorphitae } \\
\text { (Stephanos: coroa) }\end{array}$ & $\begin{array}{l}\text { Acritarcos de corpo esférico a ovóide, sem corpo interior. Apresentam um apêndi- } \\
\text { ce num dos pólos (nas formas ovóides) e, distalmente desenvolvem um processo } \\
\text { tubular de arranjos variados. A superfície é lisa ou granular. Ex.: Stelomorpha }\end{array}$ \\
\hline
\end{tabular}


para enfatizar as distintas concepções quanto às características de classificação das espécies destes dois gêneros, com importância taxonômica, tais como tamanho, morfologia dos espinhos, processos e modo de abertura. Com base em revisões e reavaliações destes táxons, dois gêneros-forma de acritarcos foram descritos: Micrhystridium, constituído por formas com uma vesícula esférica (Figura 2); e Veryhachium, incluindo formas cujo contorno da vesícula é subordinado pelo número e posição dos espinhos ou processos. Dentro deste último gênero-forma ocorre ainda uma subdivisão, com um conjunto que mantém uma forma distinta para a vesícula (Figura 3), e um segundo com processos muito amplos, onde as bases se fundem alterando o contorno da vesícula (Figura 4).

Autores como ARMSTRONG \& BRASIER (2005) e DORNING (2005) ordenaram os acritarcos em três conjuntos, que incluem um ou mais subgrupos de DOWNIE et al. (1963): Acritarcos sem processos e sem cristas ou alas, que inclui o subgrupo Sphaeromorphitae, Acritarcos com cristas ou alas, mas sem processos, que inclui os subgrupos Herkomorphitae e Pteromorphitae, e

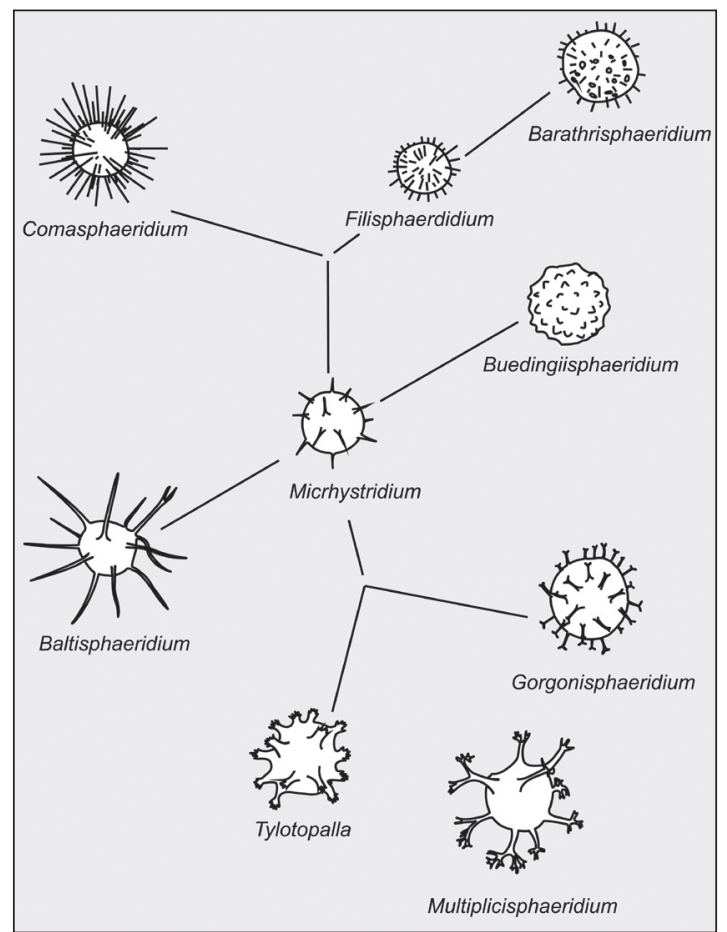

FIGURA 2 - Esquema comparativo das morfologias de alguns gêneros que constituem o gênero-forma Micrhystridium (Deflandre) Downie \& Sarjeant 1963 emend. Sarjeant 1967. As conexões das linhas sugerem similaridade morfológica e não implicam, necessariamente, em relações evolutivas ou filogenéticas (modificado de SARJEANT \& STANCLIFFE 1994).

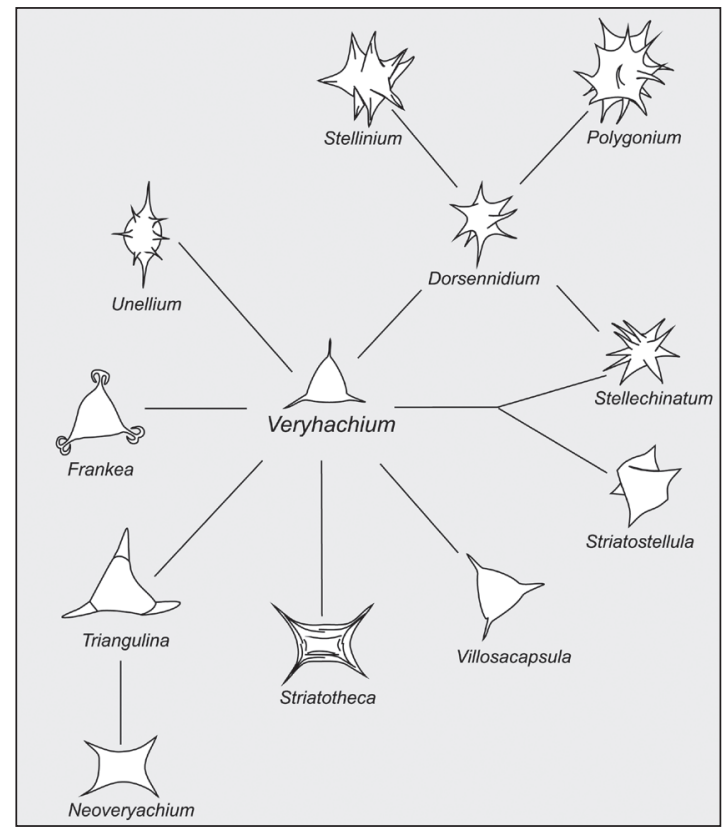

FIGURA 3 - Esquema comparativo das morfologias de alguns gêneros que constituem o gênero-forma Veryhachium (Deunff 1954) ex Downie 1959 (Downie \& Sarjeant, 1963) emend. Turner 1984; com processos de bases estreitas. As conexões das linhas sugerem similaridade morfológica e não implicam, necessariamente, em relações evolutivas ou filogenéticas (modificado de SARJEANT \& STANCLIFFE 1994).

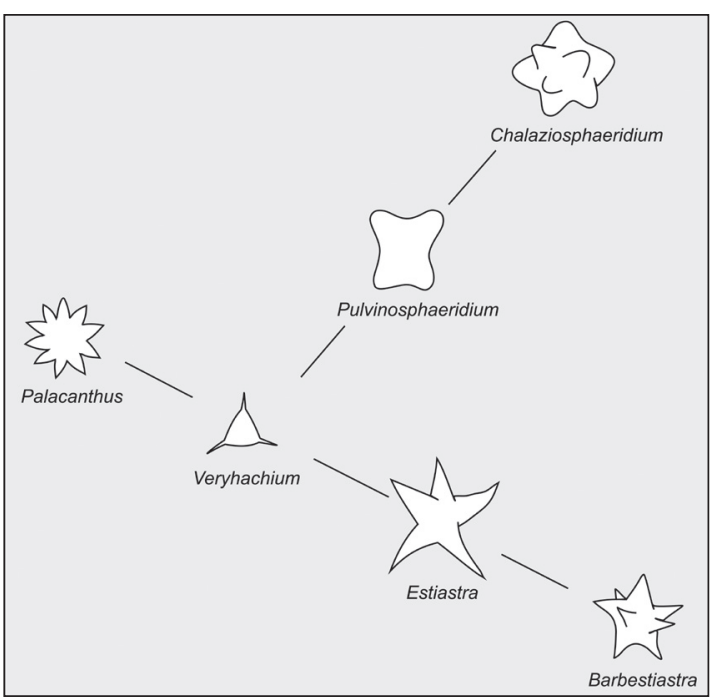

FIGURA 4 - Esquema comparativo das morfologias de alguns gêneros que constituem o gênero-forma Veryhachium (Deunff 1954) ex Downie 1959 (Downie \& Sarjeant 1963) emend. Turner 1984; com processos de bases amplas. As conexões das linhas sugerem similaridade morfológica e não implicam, necessariamente, em relações evolutivas ou filogenéticas (modificado de SARJEANT \& STANCLIFFE 1994). 
Acritarcos com processos, com ou sem cristas ou alas, que inclui os subgrupos Acanthomorphitae, Diacromorphitae, Netromorphitae, Oomorphitae, Polygonomorphitae e Prismatomorphitae. Na ordenação de ARMSTRONG \& BRASIER (2005) não foram incluídos todos os subgrupos de DOWNIE et al. (1963).

O termo Cryptarcha (grego kritos $=$ oculto, arche $=$ origem) foi proposto por DIVER \& PEAT (1979) para designar microfósseis de parede orgânica de origem desconhecida, representados por estruturas muito simples, geralmente esferas, colônias ou filamentos, registrados principalmente no PréCambriano. Nesta concepção, no Grupo Acritarcha permaneceriam as formas não esféricas ou esféricas com ornamentações e processos registradas a partir do Cambriano. De acordo com T. R. Fairchild (comunicação pessoal, 2013), os criptarcos são um grupo de conveniência separado dos acritarcos, artificialmente, podendo incluir tanto eucariotos (microalgas), como procariotos (cianobactérias). Para MARTIN (1993) o termo "Criptarco" deveria ser evitado, pois alguns dos constituintes desse grupo são encontrados até o Recente. A conceituação e manutenção desse termo revela-se tema controverso, não constituindo objeto direto da presente análise.

\section{DISTRIBUIÇÃO ESTRATIGRÁFICA}

Os acritarcos estão registrados desde o PréCambriano até o Recente (Figura 5), com ampla distribuição mundial. STROTHER (1994) ampliou o uso do termo "palinomorfos", de modo a incluir, além dos microfósseis de parede orgânica recuperados a partir do método de maceração, aqueles de parede robusta preservados em cherts. Dessa forma, muitos dos criptarcos proterozoicos corresponderiam a acritarcos, o que implica em sua origem a partir do Proterozoico (indistinto), juntamente com o registro de cianobactérias. Segundo RIEGEL (2008), entre o Cambriano e o Devoniano, o microplâncton marinho apresentou grande irradiação e diversificação de táxons, especialmente entre os acritarcos, os quais foram pontuados por poucos eventos de extinção, possivelmente associados a mudanças climáticas.

São abundantes e muito diversificados nas rochas sedimentares paleozoicas, com significativa dominância entre o Cambriano e o Devoniano. No limite entre o Devoniano e o Carbonífero ocorreu uma redução drástica da diversidade do grupo, coincidindo com processos tectônicos durante os eventos de formação do Pangea e a simultânea irradiação das plantas terrestres no final do Devoniano. Com isto, podem ter ocorrido alterações na dispo- nibilidade de nutrientes nos oceanos, importante fator controlador do "blackout" dos acritarcos no final do Paleozoico (Figura 6).

A partir do Mississipiano, o grupo sofre acentuado declínio, o que foi denominado por RIEGEL (2008) como "blackout" do fitoplâncton.

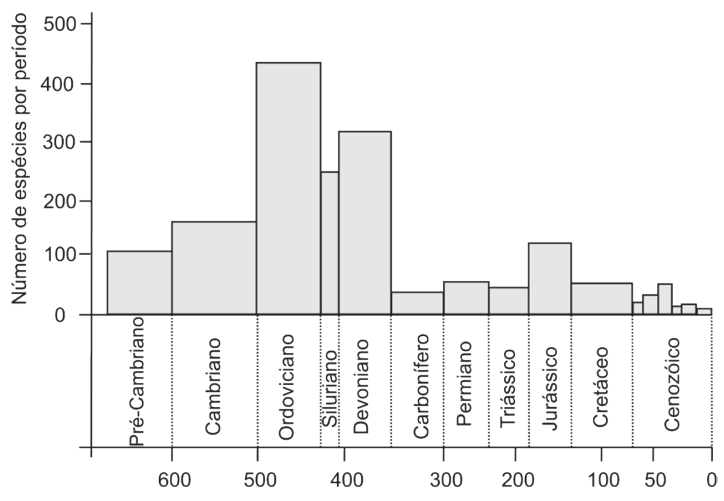

FIGURA 5 - Diversidade das espécies de acritarcos através do tempo geológico (modificado de CRUZ 2011, com base em TAPPAN \& LOEBLICH 1973 e TAPPAN 1980).

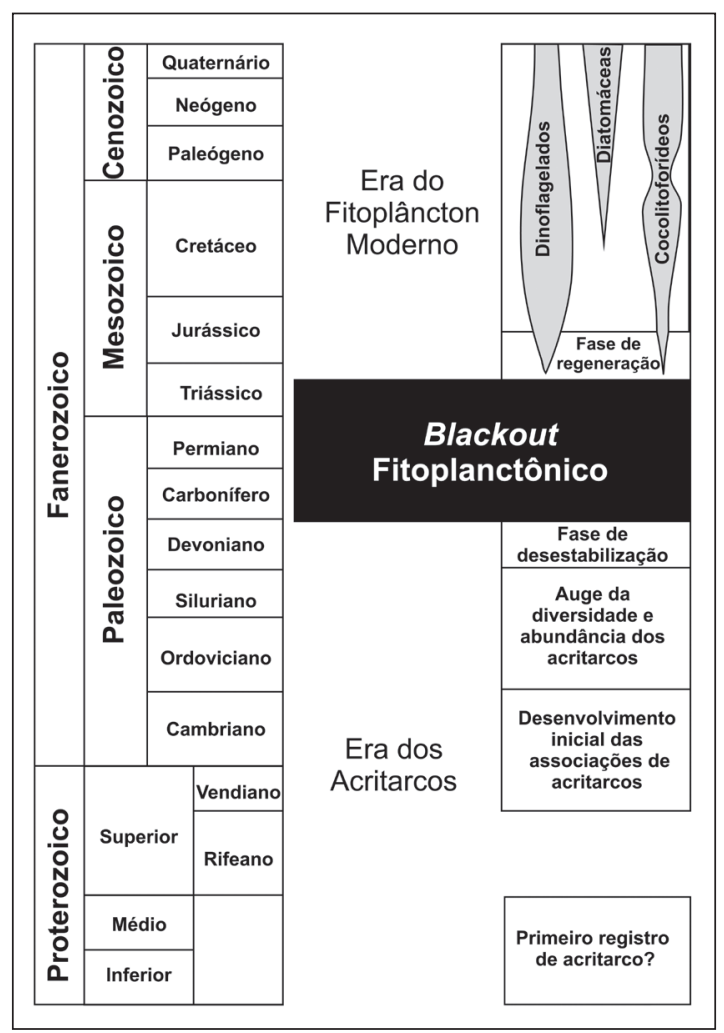

FIGURA 6 - História evolutiva dos principais elementos constituintes do fitoplâncton, conforme terminologia e conceitos de RIEGEL (2008), com modificações. 
Nas últimas décadas, com o incremento das informações sobre os requerimentos nutricionais de algas eucarióticas modernas, suas implicações e aplicação também aos grupos fósseis, foi possível ampliar as correlações e as interpretações sobre este processo de desaparecimento ou diminuição na diversidade relativa. De acordo com RIEGEL (2008), alguns fatores associados aos eventos tectônicos do Pangea e acontecimentos sucessivos foram responsáveis pelo colapso da produtividade marinha primária a partir do limite Devoniano-Carbonífero: a) retenção de nutrientes na superfície com o desenvolvimento dos solos e a expansão da flora terrestre; b) significativa redução de nutrientes devido à formação de extensos depósitos de folhelhos negros no Devoniano Médio e Superior; c) fechamento dos oceanos nas baixas latitudes; d) mudanças no clima, circulação oceânica e propagação das camadas de baixa salinidade associadas ao derretimento das camadas de gelo do final do Devoniano; e) considerável retenção de carbono orgânico e de nutrientes em depósitos de carvão no Pennsilvaniano e Permiano Inferior; f) propagação do clima glacial entre o Mississipiano e o Permiano Médio, seguido do clima continental quente e seco com amplos depósitos de redbeds e evaporitos durante o Permiano Superior e Triássico Inferior; g) retenção de sedimentos em extensas bacias continentais; h) flutuações glacio-eustáticas do nível do mar e consistente redução do nível de base durante a longa glaciação do Permo-Carbonífero e o auge da formação do Pangea; i) transferência de sedimentos carregados de nutrientes para o mar profundo durante o nível de mar baixo, quando a linha de costa está localizada na margem continental.

Para STROTHER (2008), de todos os organismos marinhos, o grupo dos acritarcos foi o mais sensível a certas condições químicas do oceano, uma vez que seu metabolismo fotoautotrófico requer luz, bem como nutrientes inorgânicos e uma fonte de carbono inorgânico disponível. Em geral, proliferações (florações ou "blooms") desses organismos são associadas com regiões de ressurgência de nutrientes no oceano, estimuladas por fatores climáticos. A diversidade do fitoplâncton durante o Fanerozoico é mais intimamente relacionada com mudanças em larga escala na química das águas do oceano do que com modelos de fluxo trófico.

RIEGEL (2008) concluiu que a dominância relativa, a abundância e a diversidade do fitoplâncton marinho são controladas pela transferência de nutrientes dos continentes para os oceanos, pelo estado de oxigenação destes e, consequentemente, pela disponibilidade de nitrogênio reduzido e ferro, além da estratificação termal. O "blackout" que ocorreu após o Devoniano pode ser considerado como uma fase de baixa produtividade dos acritarcos.

Algumas correntes de pesquisadores se opuseram ao conceito deste "blackout", com argumentos baseados em pesquisas com biomarcadores (MOLDOWAN et al. 1996, SCHWARK \& EMPT 2002), ou através de estudos sobre os ciclos de vida de dinoflagelados e estrutura trófica (SERVAIS et al. 2006).

Embora houvesse oposição à teoria do "blackout", RIEGEL (2008) considerou que uma preservação seletiva não poderia ser considerada causa significante para o desaparecimento dos acritarcos no limite Devoniano-Carbonífero. O contínuo registro de algas prasinofíceas, bem como de esporomorfos (oriundos de plantas terrestres) em várias seções, demonstram que existiram condições apropriadas para a manutenção, da mesma forma, destes cistos de parede orgânica nesse intervalo de tempo.

No intervalo Pennsilvaniano/Permiano da Bacia do Paraná, bem como na maioria dos depósitos coevos de outras bacias em nível mundial, a interpretação do "blackout" do fitoplâncton é apoiada se for considerada a diversidade em nível de gênero. Os gêneros mais comuns nesses estratos são Micrhystridium (DEFLANDRE) DOWNIE \& SARJEANT 1963 emend. SARJEANT 1967 e Veryhachium (DEUNFF 1954) ex DOWNIE 1959 (DOWNIE \& SARJEANT, 1963) emend. TURNER 1984, com ausência completa daquelas mais comuns nas associações pré-carboníferas. Contudo, a variedade de formas incluídas nesses dois gêneros é extremamente grande, de modo a induzir a aceitação do conceito de "complexos" para neles serem abarcados diversos morfotipos (SARJEANT \& STANCLIFFE 1994, FÉLIX 2012).

Desde o Devoniano e após um intervalo de aproximadamente 130 milhões de anos, a diversidade do fitoplâncton foi gradualmente restaurada com o aparecimento dos dinoflagelados a partir do Triássico Superior e, um pouco mais tarde, dos cocolitoforídeos (Jurássico) e das diatomáceas (a partir do Cretáceo). Evidências do fitoplâncton recente sugerem que os grupos dominantes diferem daqueles do Paleozoico em seus requerimentos nutricionais e que mudanças fundamentais na composição química dos oceanos foram papel importante neste processo (RIEGEL 2008).

Representantes de alguns gêneros de acritarcos paleozoicos são registrados até o Recente em depósitos transicionais e marinhos, geralmente com baixa frequência e com atribuição taxonômica aberta. No Brasil, CANCELLI et al. (2012) registraram acritarcos do gênero Micrhystridium 
em sedimentos holocênicos da planície costeira sul-catarinense; MEDEANIC (2006) constatou a presença do mesmo gênero em áreas estuarinas da Lagoa dos Patos, indicando influência de salinidade nestes ambientes. Esses registros constituem alguns dos exemplos de ocorrências pós-devonianas desses acritarcos em bacias brasileiras.

\section{APLICAÇÕES NAS GEOCIÊNCIAS}

\subsection{Potencial bioestratigráfico}

Segundo PLAYFORD (2003), a ampla distribuição, a diversidade e a história de especiações e extinções durante longo tempo geológico fazem dos acritarcos um grupo com alto potencial para zoneamentos bioestratigráficos, tanto regionais como globais, especialmente para o Cambriano, Ordoviciano, Siluriano e o Devoniano. Diversos esquemas de zoneamentos bioestratigráficos, formais e informais, foram propostos para depósitos destas idades, baseados principalmente em zonas de associação e de intervalo (MOLYNEUX et al. 1996).

O registro de acritarcos em sedimentos précambrianos tem auxiliado nas interpretações biocronoestratigráficas. A partir dos estudos de LE HÉRISSÉ (1989) e MOCZYDLOWSKA (1991), em que a análise taxonômica detalhada é associada à estratigrafia, biozoneamentos baseados em acritarcos tornaram-se úteis, demonstrando um melhor potencial dos acritarcos com relação aos estromatólitos.

Para o Pré-Cambriano brasileiro, FAIRCHILD et al. (1996) apresentaram uma síntese de novas ocorrências de microfósseis proterozoicos no Cráton de São Francisco e regiões adjacentes, incluindo diversos táxons atribuídos a cianobactérias e alguns poucos a acritarcos. Os táxons atribuídos a acritarcos são caracteristicamente arredondados e foram dispostos nos gêneros Leiosphaeridia, Protosphaeridium, Stictosphaeridium, Trachysphaeridium e Vandalosphaeridium.

Posteriormente, SIMONETTI \& FAIRCHILD (2000) publicaram um estudo sistemático de microfósseis pré-cambrianos no Brasil. A qualidade da preservação e abundância da matéria orgânica permitiram interpretações significativas dos hábitos e habitats desses microfósseis, com implicações paleoecológicas. As formas atribuídas a acritarcos, identificados como Leiosphaeridia e Pterospermopsimorpha, compreendem vesículas geralmente circulares ou mais raramente elípticas. Mais recentemente, GAUCHER et al. (2003) apresentou a integração de dados paleontológicos entre Brasil e Uruguai para o final do Pré-Cambriano. Os espécimes descritos como acritarcos foram atribuídos à Leiosphaeridia, gênero atualmente alocado nas algas prasinofíceas, além de outros táxons correspondentes à vesículas circulares, que também guardam características similares desta classe. Desta forma, conclui-se que poucos dos espécimes descritos para o Pré-Cambriano brasileiro são relativos ao Grupo Acritarcha.

As pesquisas pioneiras sobre os depósitos paleozoicos brasileiros foram marcadas pelo reconhecimento de diversas formas de acritarcos e algas prasinofíceas, muitas das quais atribuídas a novas espécies e até gênero. A maior parte desses estudos é proveniente de material de subsuperfície das bacias intracratônicas do norte e nordeste brasileiros. Diversos trabalhos foram apresentados por Ignácio Machado Brito, cuja lista de publicações é extensa (e.g. BRITO 1965; BRITO \& SANTOS 1965; BRITO 1967a, b; BRITO 1969; BRITO \& QUADROS 1984), em estudos vinculados à Divisão de Geologia e Mineralogia do Departamento Nacional de Produção Mineral. Trata-se de estudos taxonômicos em épocas em que pouco era conhecido sobre a origem biológica desses táxons. Contudo, seu potencial bioestratigráfico foi progressivamente confirmado, subsidiando estudos desenvolvidos posteriormente (e.g. QUADROS 1985).

A maioria dos trabalhos realizados no Paleozoico brasileiro aponta os acritarcos como excelentes guias bioestratigráficos para o Ordoviciano na Bacia do Solimões (QUADROS 1986); Siluriano nas bacias do Parnaíba e Amazonas (BRITO 1967a, QUADROS 1985, CARDOSO 2002) e Devoniano nas bacias do Parnaíba, Amazonas, Paraná e Solimões (BRITO 1967b, 1969; QUADROS 1982; QUADROS 1985; OLIVEIRA 1997; QUADROS 1999; MAULLER 2008; RUBINSTEIN et al. 2008). Muitos desses zoneamentos foram baseados em espécies atribuídas a acritarcos e posteriormente reinterpretadas como algas prasinofíceas (QUADROS 1985, OLIVEIRA 1997), em associação com outros acritarcos sensu strictu. No noroeste da Argentina, o trabalho de ARÁOZ \& VERGEL (2006) constitui bom exemplo de aplicação bioestratigráfica para estratos cambrianos a ordovicianos (formações Casa Colorada e Alfarcito, em Jujuy) com base em acritarcos, associados a diversas espécies de algas prasinofíceas. Na Argentina RUBINSTEIN \& BRUSSA (1999) integraram palinomorfos e graptolitos em uma análise bioestratigráfica no Siluriano da Bacia Precordilheira Central. Ainda no Siluriano RUBINSTEIN (1995) apresentou a relação entre acritarcos e esporomorfos com proposições de idade. Além dos trabalhos já citados, outros, como RUBINSTEIN (2000) e RUBINSTEIN \& PUENTE 
(2008), também contribuíram para os estudos bioestratigráficos na Argentina. Após o Devoniano, os acritarcos não são utilizados para fins bioestratigráficos, uma vez que outros grupos são mais abundantes e com maior potencial de datação e correlação, tais como os esporomorfos (a partir do Carbonífero) e dinoflagelados (a partir do Triássico).

Vale observar que nos depósitos cambrianos a devonianos, a bioestratigrafia do grupo está geralmente integrada a distribuição de outros elementos marinhos, tais como quitinozoários (PARIS et al. 2007), graptozoários (VECOLI 1996) e invertebrados fósseis, tais como os trilobitas (RAEVSKAYA \& GOLUBKOVA 2006, RAEVSKAYA \& SERVAIS 2009), e com associações terrestres de miósporos (RICHARDSON et al. 1981).

\subsection{Potencial paleoambiental}

De acordo com CARDOSO (2005), com exceção de alguns registros de acritarcos de água doce no Permiano Superior das montanhas Príncipe Charles na Antártica, em turfas do Pleistoceno na Inglaterra e em depósitos lacustres do Holoceno da Austrália, todos os demais foram encontrados em sedimentos marinhos ou em águas salobras.

Em combinação com palinomorfos de origem continental (esporos e grãos de pólen), os acritarcos podem ser utilizados para a determinação da proximidade da linha de costa. Isoladamente não são bons indicadores de profundidade, pois são planctônicos e requerem fatores fisiológicos para realização de fotossíntese, limitando seu hábitat à zona fótica (WILLIAMS \& SARJEANT 1967).

Com base em assembleias devonianas do Canadá, STAPLIN (1961) observou diferenças nos padrões morfológicos dos acritarcos, atribuídas à distância relativa da linha de costa. Formas esféricas lisas ou com ornamentação pouco pronunciada são mais abundantes nas fácies mais proximais, enquanto aquelas com ornamentação mais proeminente e diversa foram registradas em ambientes mais distais. Em termos de diversidade, segundo WALL (1965), as variações na composição das associações de acritarcos podem ser associadas a ciclos deposicionais regressivo-transgressivos. Conjuntos com menor diversidade ocorrem em depósitos clásticos grossos, característicos de fases regressivas de deposição, enquanto grupos mais diversificados ocorrem em margas e argilas, fácies características de depósitos transgressivos.

Para MONTENARI \& LEPPIG (2003), as associações de acritarcos são controladas tanto por parâmetros sedimentológicos como ecológicos, e divididas em quatro tipos característicos de fácies: costeiras de águas rasas, plataformais proximais, plataformais distais e bacinais de águas profundas (Figura 7). Os autores observaram que a ocorrência dos acritarcos varia de forma diretamente dependente da granulometria. Segundo esse modelo, em fácies costeiras de águas rasas, caracterizada por eventos de maior energia, predominam representantes do subgrupo Sphaeromorphitae. Na fácies plataformais proximais observa-se aumento na diversidade e correspondente diminuição da dominância de alguns táxons. Nesta fácies, os sedimentos são de granulometria mais fina, predominando os subgrupos Polygonomorphitae e Netromorphitae, com poucos representantes de Sphaeromorphitae. Já na fácies plataformal distal, a dominância alcança seu mínimo e, a diversidade, por outro lado, atinge seu ponto máximo. Para os autores supracitados, em fácies bacinais de águas profundas ocorre pequena diversidade, como na fácies de águas rasas.

O uso deste modelo pode ser limitado pela similaridade entre as associações de águas rasas e águas profundas. O estudo de palinofácies, que inclui a contagem e a análise do significado textural (forma, grau de arredondamento, estado de preservação) de todos os componentes da matéria orgânica presentes nas lâminas (palinomorfos, fitoclastos e matéria orgânica amorfa, quando presentes), é ferramenta indispensável para essas interpretações, além de dados sobre a sedimentologia e estratigrafia de sequências.

Em uma amostra palinológica representativa de ambiente marinho, associações que apresentam abundância e elevado grau de preservação de esporomorfos (esporos e grãos de pólen) e poucos elementos fitoplanctônicos indicam ambientes próximos à costa, com uma maior participação de palinomorfos vinculados à vegetação continental. Conjuntos com maior representatividade do fitoplâncton demonstram condições relativamente mais afastadas da costa. Contudo, em águas profundas os acritarcos são menos abundantes. Por outro lado, a quantidade de palinomorfos terrestres está também subordinada ao aporte continental, constituindo outra variável na análise paleoambiental integrada.

Para a Bacia do Paraná, CAZZULO-KLEPZIG et al. (1989) observaram, com base em acritarcos, o início de uma fase transgressiva, abrangendo o intervalo estratigráfico correspondente ao topo da Formação Palermo até a porção inferior da Formação Irati, no Rio Grande do Sul e sul de Santa Catarina, Brasil, com ocorrência marcante dos gêneros Micrhystridium e Veryhachium, intervalo considerado um marco estratigráfico na bacia. Embora a expressão do registro 


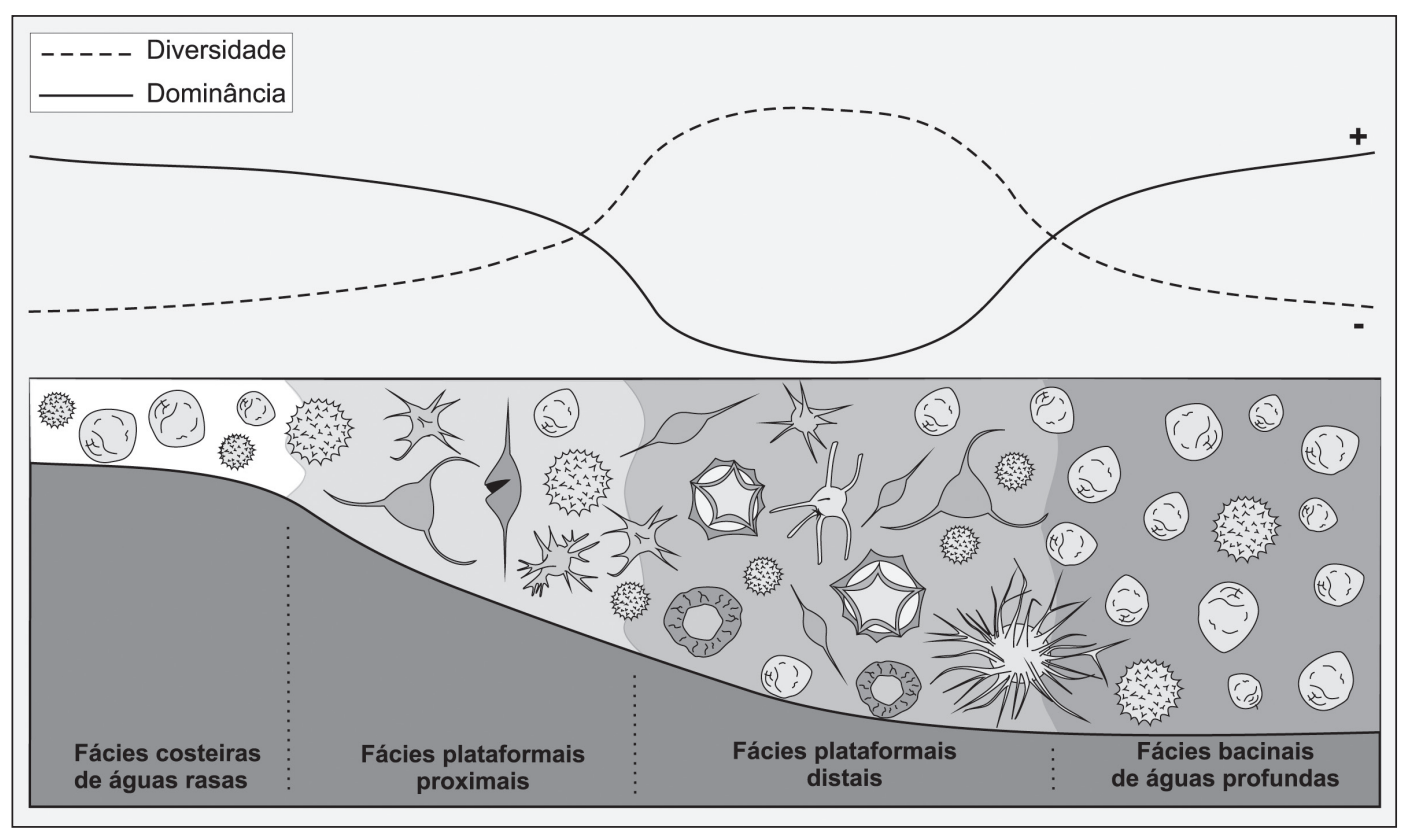

FIGURA 7 - Distribuição dos acritarcos nos ambientes plataformais e sua relação de dominância e diversidade (modificado de MONTENARI \& LEPPIG 2003).

dos acritarcos nessas duas unidades seja muito similar, são limitadas por significativa discordância de $3^{\mathrm{a}}$ ordem (HOLZ \& DIAS 1998), denominada SB5 por HOLZ et al. (2010).

HOLZ \& DIAS (1998) estudaram o significado do microplâncton nos depósitos do Permiano Inferior do Rio Grande do sul (Brasil), verificando o padrão de distribuição destas formas em comparação com o modelo de estratigrafia de sequências. Acritarcos dos gêneros Micrhystridium e Veryhachium foram registrados em tratos de sistema de mar alto, relacionados com a maior extensão de águas marinhas e maior profundidade, condição paleoecológica ideal para o desenvolvimento deste grupo. Os autores enfatizaram a relação direta entre o registro palinológico, a estratigrafia de sequências e as implicações tafonômicas, com forte reflexo na interpretação das mudanças paleoambientais, destacando a palinologia como importante ferramenta na integração de dados estratigráficos. O modelo apresentado pelos autores é válido para a Bacia do Paraná; contudo a presença e abundância de acritarcos em sistemas de mar alto são dependentes de outros fatores, tais como disponibilidade de nutrientes e paleoclima.

$\mathrm{Na}$ análise inédita de amostras selecionadas de testemunhos de sondagem do poço perfurado no sul do Estado do Rio Grande do Sul, HN-25-RS, realizada por FÉLIX (2012), foi constatado que nos níveis superiores da Formação Palermo até a porção média da Formação Irati ocorrem acritarcos dos complexos
Micrhystridium e Veryhachium, mais abundantes na base da Formação Irati. Estes dados estão de acordo com CAZZULO-KLEPZIG et al. (1989) e HOLZ \& DIAS (1998), corroborando a identificação do marco "palinoestratigráfico" (grifo dos autores desse trabalho) permiano da Bacia do Paraná.

\subsection{Paleogeografia e paleoclima}

O modelo de distribuição de acritarcos e algas prasinofíceas representa importante ferramenta para a paleogeografia e reconstruções paleoclimáticas.

A distribuição dos representantes recentes do fitoplâncton é base para estudo dos processos que ocorreram nos seus análogos fósseis, e está relacionada a fatores como temperatura, disponibilidade de nutrientes, turbidez, salinidade, luz, profundidade, entre outros. A maioria das comunidades fitoplanctônicas atuais mostra claro controle latitudinal (MOLYNEUX et al. 1996).

Bioprovíncias propostas com base na distribuição geográfica e estratigráfica de espécies de acritarcos foram estabelecidas para o Ordoviciano (LI 1987, TONGIORGI et al. 1995), Siluriano (CRAMER 1968, CRAMER \& DIEZ 1972, VAVRDOVÁ 1974) e Devoniano (VAVRDOVÁ \& ISAACSON 1999).

Segundo VAVRDOVÁ \& ISAACSON (1999), a caracterização de províncias, baseada em morfotipos sensíveis a determinadas temperaturas, pode ajudar no reconhecimento de posições dos paleocon- 
tinentes e paleolatitudes. $\mathrm{Na}$ ausência de registros abundantes de macrofósseis e microfósseis calcáreos, fosfáticos e silicosos guias, bem como de informações paleomagnéticas mais calibradas, estas reconstruções tornam-se dependentes dos dados de distribuição de microfósseis orgânicos. No estudo realizado por esses autores foi proposto um modelo baseado na distribuição de Umbellasphaeridium saharicum no Devoniano Superior, que diferenciou e caracterizou uma comunidade de microplâncton de altas latitudes entre o Frasniano e o Famenniano no Reino Malvinocáfrico, em regiões do Gondwana ocidental e Laurussia meridional.

LE HÉRISSÉ et al. (1997) observaram que os processos de provincialismo são dependentes do arranjo continental, das flutuações climáticas globais e, provavelmente, de mudanças geoquímicas e na circulação oceânica. Os autores constataram que os principais aspectos da paleogeografia do intervalo Siluriano-Devoniano, entre eles o fechamento do Oceano Iapetus, e consequentes mudanças ambientais, foram suficientemente fortes para influenciar na distribuição das associações do fitoplâncton. No Siluriano Superior, assembleias muito diferenciadas têm sido reconhecidas em ambientes plataformais e o seu controle, atribuído à posição latitudinal e temperatura da água.

A Bacia do Paraná sediou, no Brasil, a fauna da Província Malvinocáfrica, definida pelo endemismo ou baixa diversidade de certos grupos de invertebrados marinhos devonianos, presumivelmente adaptados a águas frias dominando elevadas paleolatitudes no hemisfério sul. Esta província floresceu essencialmente no hemisfério sul (América do Sul - regiões do território brasileiro, sul do Peru, Bolívia, Paraguai, Uruguai, Argentina, Ilhas Malvinas - Antártica e África do Sul), durante o Devoniano médio e final. Uma paleofauna peculiar de invertebrados marinhos, sobretudo trilobitas e braquiópodes (MELO 1988), adaptados a águas rasas, frias e altas latitudes, caracterizou essa província.

Em OLIVEIRA (1997) é apresentada uma proposta de reconstrução paleogeográfica para a sequência marinha devoniana da Bacia do Paraná, baseada na distribuição dos acritarcos e algas prasinofíceas, ainda inédita. A autora ressaltou as vantagens do estudo com este grupo como, por exemplo, o hábito planctônico, distribuição cosmopolita e de pequeno tamanho, além do grande número de espécimes em uma amostra. Embora haja vantagens, poucos foram os estudos realizados com esses microfósseis que apresentaram propostas paleobiogeográficas.

Na figura 8A é apresentada a reconstrução paleogeográfica para o Emsiano (Devoniano Inferior) da Bacia do Paraná no Brasil e áreas adjacentes, com base na distribuição de braquiópodes e trilobitas (MELO 1988). Esta interpretação foi corroborada por OLIVEIRA(1997), na reconstrução ilustrada na figura 8B, baseada na distribuição de acritarcos e algas prasinofíceas. Diferenças menores entre as duas reconstruções são, provavelmente, devido às distintas amostragens e/ou detalhamento na elaboração dos mapas.
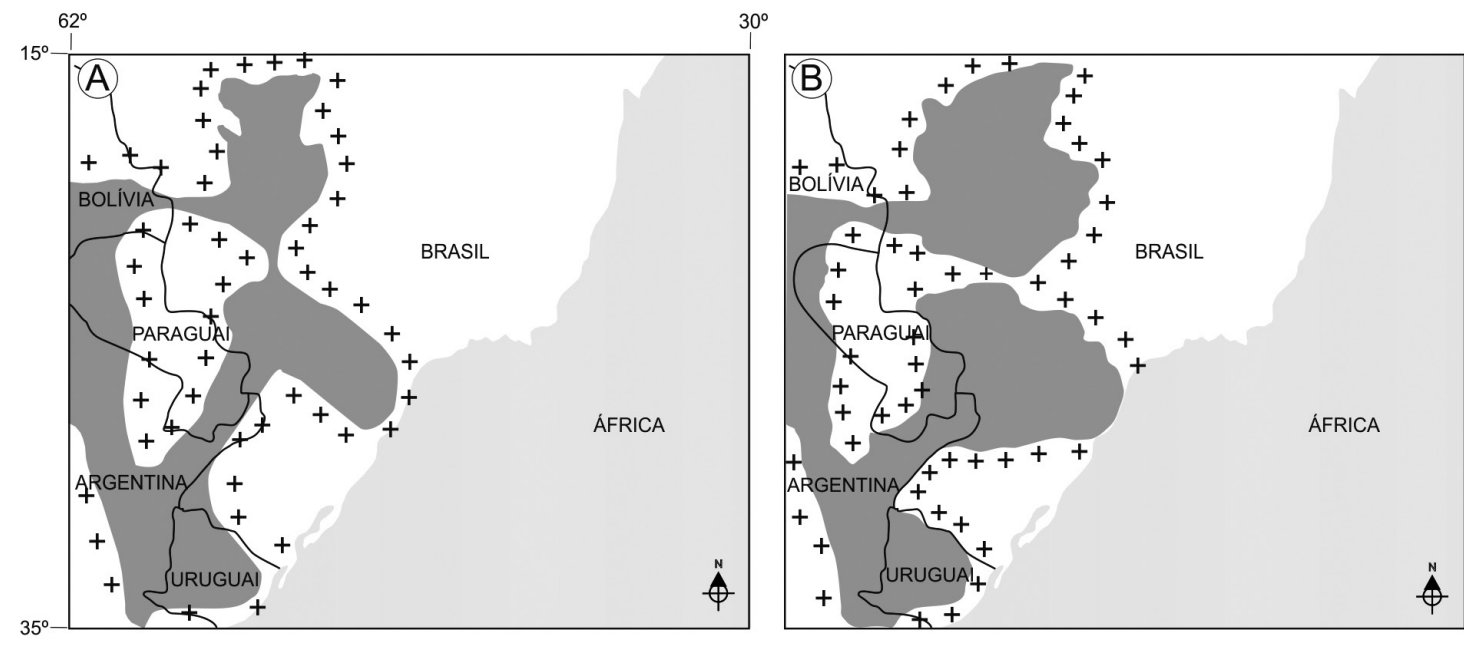

Legenda

\section{Transgressão marinha}

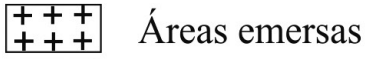

FIGURA 8 - Reconstruções paleogeográficas da Bacia do Paraná para o Emsiano, baseadas em A) braquiópodes e trilobitas (MELO 1988) e B) acritarcos (OLIVEIRA 1997). 


\section{CONSIDERAÇÕES FINAIS}

A taxonomia dos acritarcos tem sido relativamente pouco estudada apesar dos extensos e espessos depósitos sedimentares paleozoicos nas bacias brasileiras. A maior parte dos trabalhos sobre esse tema é anterior à década de 1980, tratando-se, principalmente, das bacias do norte e nordeste. Nesse sentido, a Bacia do Paraná apresenta-se fortemente prejudicada, com poucos estudos nos depósitos com ricas associações de acritarcos e publicações ainda inéditas (OLIVEIRA 1991, 1997; MAULLER 2008). Muitos dos táxons identificados como acritarcos são considerados atualmente como pertencentes à Classe Prasinophyceae. Contudo, as interpretações bioestratigráficas e/ou paleoambientais advindas não são afetadas, uma vez que constituem elementos de associações, na maioria das vezes, de origem marinha, juntamente com outros fósseis, sejam de natureza palinológica (quitinozoários, esporos) ou não.

Para o intervalo Pennsilvaniano-Permiano da Bacia do Paraná, as associações de acritarcos, representadas por espécimes atribuídos aos gêneros-forma Micrhystridium e Veryhachium, são restritos a determinados níveis estratigráficos, com significado paleoecológico e estratigráfico. Em comparação com depósitos pré-carboníferos, as assembleias têm pouca riqueza (em nível genérico), embora representados por abundância de espécimes. Contudo, essas ocorrências são restritas a determinados níveis. Nota-se, que muitos níveis reconhecidamente marinhos por outras ferramentas paleontológicas e estratigráficas na bacia, não apresentam registros de acritarcos. Dentre esses, destacam-se os depósitos do Subgrupo Itararé de idade pennsilvaniana, tais como em Itaporanga (DI PASQUO et al. 2003) e Araçoiaba da Serra (SOUZA et al. 2003), ambos com registros de formas atribuídas a acritarcos, que são referentes a algas prasinofíceas (Deusilites spp.). Essas constatações podem estar diretamente relacionadas ao "blackout" do fitoplâncton sustentado por diversos autores, bem como serem resultantes de limitações impostas pelas condições climáticas mais frias da glaciação do Paleozoico Superior do Gondwana.

Além disso, tornam-se necessárias reinterpretações sobre as idades de alguns registros de espécimes atribuídos a acritarcos no Subgrupo Itararé, uma vez que parte dessas ocorrências é nitidamente oriunda de retrabalhamento de estratos devonianos, tal como demonstrado por SOUZA \& PETRI (1998).

\section{AGRADECIMENTOS}

Este trabalho faz parte da Tese de Doutoramento da primeira autora junto ao Programa de Pós-Graduação em Geociências da Universidade Federal do Rio Grande do Sul (UFRGS). Os autores agradecem à Companhia de Pesquisa de Recursos Minerais (CPRM) pela concessão de amostras, ao Conselho Nacional de Desenvolvimento Científico (CNPq) pela bolsa de doutorado (140657/20070 ) e recursos via projetos de pesquisa (Processos 480385/2010-6 e 401769/2010-0). Finalmente, os autores agradecem a Dra. Márcia Longhim e Dr. Thomas Rich Fairchild pelos comentários e sugestões construtivas sobre o manuscrito.

\section{REFERÊNCIAS BIBLIOGRÁFICAS}

ARÁOZ, L.; VERGEL, M.M. 2006. Palinología de la transición cambro-ordovícica en la Quebrada de Moya, Cordillera Oriental, Argentina. Revista Brasileira de Paleontologia, 9: 1-8.

ARMSTRONG, H.A.; BRASIER, M.D. 2005. Microfossils. Blackwell Publishing, Oxford, $2^{a}$ ed., 296 p.

BOALCH, G.T.; PARKE, M. 1971. The Prasinophycean genera (Chlorophyta) possibly related to fossil genera, in particular the genus Tasmanites. In: A. Farinacci (ed.) Proceedings of the II Planktonic Conference, p. 99-105.

BRITO, I.M. 1965. Novos microfósseis devonianos do Maranhão. Universidade da Bahia, Escola de Geologia, Publicação Avulsa, 2: 1-4.

BRITO, I.M. 1967a. Silurian and Devonian Acritarcha from Maranhão Basin, Brazil. Micropaleontology, 13(4): 473-482.

BRITO, I.M. 1967b. Novo subgrupo de Acritarcha do Devoniano do Maranhão. Anais da Academia Brasileira de Ciências, 39(1): 163-166.

BRITO, I.M. 1969. Un nouveau sous-groupe d'acritarche. Boletim de Geologia - UFRJ, 4: 11-13.

BRITO, I.M.; QUADROS, L.P. 1984. Novas ocorrências de Acritarchae no Devoniano da Bacia do Parnaíba. Boletim do IG-USP, 15: 15-19.

BRITO, I.M.; SANTOS, A.S. 1965. Contribuição ao conhecimento dos microfósseis Silurianos e Devonianos da Bacia do Maranhão. I. Os 
Nethromorphitae (Leiofusidae). Notas preliminares e Estudos, DGM, DNPM, 129: 1-29.

CANCELLI, R.R.; SOUZA, P.A.; NEVES, P.C.P. 2012. Fungos, criptógamas e outros palinomorfos holocênicos (7908 \pm 30 anos AP-atual) da Planície Costeira sul-catarinense, Brasil. Acta Botanica Brasílica (Impresso), 26: 20-37.

CARDOSO, T.R.M. 2002. Acritarcos Silurianos da Bacia do Amazonas: Sistemática e Bioestratigrafia. Instituto de Geociências, Universidade Federal do Rio Grande do Sul, Tese de Doutorado, $169 \mathrm{p}$.

CARDOSO, T.R.M. 2005. Acritarcos do Siluriano da Bacia do Amazonas: Bioestratigrafia e Geocronologia. Arquivos do Museu Nacional, 63(4): 727-759.

CAZZULO-KLEPZIG， M.; PICCOLI， A.E.M.; MARQUES-TOIGO, M. 1989. Reconhecimento de um marco estratigráfico com significado paleoecológico no Permiano da Bacia do Paraná (Grupos Guatá e Passa Dois). In: SBP, CONGRESSO BRASILEIRO DE PALEONTOLOGIA, 11, Curitiba, Anais, 2: 971-982.

CRAMER, F.H. 1968. Geron, an acritarch genus from the Silurian. Bulletin de la Société Belge de Géologie, 77: 217-25.

CRAMER, F.H.; DÍEZ de CRAMER, M.C. 1972. North American Silurian palynofacies and their spatial arrangement: acritarchs. Palaeontographica Abt. B, 138: 107-180.

CRUZ, N.M. 2011. Acritarcos. In: I.S. Carvalho (ed.) Paleontologia. Editora Interciência, Rio de Janeiro, 2: 221-228.

DEFLANDRE, G. 1947. Le probleme des Hystrichosphkres. Bulletin de l'lnstitut oceánographique, 918:1-23.

DEFLANDRE, G. 1954. Systématique des Hystrichosphaeridés: surl' acception du genre Cymatiosphaera O. Wetzel. Compte rendu sommaire et Bulletin de la Societé Géologique de France, 4: 257-258.

DEUNFF, J. 1954. Veryhachium, genre nouveau d'Hystrichosphères du Primaire. Compte Rendu Sommaire de la Société géologique de France, 13: 305-306.
DI PASQUO, M.M.; AZCUY, C.L.; SOUZA, P.A. 2003. Palinología del Carbonífero Superior del Subgrupo Itararé en Itaporanga, Cuenca Paraná, Estado de São Paulo, Brasil. Parte 1: sistemática de esporas y paleofitoplancton. Ameghiniana, 40(3): 277-296.

DIVER, W.; PEAT, C. 1979. On the interpretation and classification of Precambriam organicwalled microfossils. Geology, 7: 401-404.

DORNING, K.J. 2005. Acritarchs. In: R. Selley, L. Cocks \& I Pilmer. (eds.) Encyclopedia of Geology. Amsterdam, Elsevier, 1: 418-428.

DOWNIE, C. 1959. Hystrichospheres from the Silurian Wenlock Shale Engkand. Palaeontology, 2(1): 56-71.

DOWNIE, C. 1973. Observations on the nature of acritarchs. Palaeontology, 16: 239-259.

DOWNIE，C.; SARJEANT, W.A.S. 1963. On the interpretation and status of some hystrichospheregenera. Palaeontology, 6: 83-96.

DOWNIE, C.; WILLIAMS, G.L.; SARJEANT, W.A.S. 1961. Classification of fossil microplankton. Nature, 192: 471.

DOWNIE, C.; EVITT, W.R.; SARJEANT, W.A.S. 1963. Dinoflagellates, hystrichospheres and the classification of the acritarchs. Publications in Geological Sciences, 7: 1-16.

EISENACK, A. 1958. Tasmanites Newton 1875 und Leiosphaeridia n.g. als Gattungen der Hystrichosphaeridea. Palaeontographica Abt. A, 110: 1-19.

EISENACK, A. 1972. Kritische Bemerkung zur Gattung Pterospermopsis Chlorophyta (Prasinophyceae). Neues Jahrbuch für Geologie und Paläontologie, Monatsheft, 10: 596-601.

EVITT, W.R. 1963. A discussion and proposals concerning fossil dinoflagellates, hystrichospheres, and acritarchs, II. National Academy of Sciences, 49: 158-164.

FAIRCHILD, T.R.; SCHOPF, J.W.; MILLER, J.S.; GUIMARÃES, E.M.; EDWARDS M.D.; LAGSTEIN, A.; LI, X.; PABST, M.; MELOFILHO, L.S. 1996. Recent discoveries of Pro- 
terozoic microfossils in south-central Brazil. Precambrian Research, 80: 125-152.

FÉLIX, C.M. 2012. Nova abordagem para o tratamento taxonômico de determinadas espécies de palinomorfos do Paleozóico Superior do Gondwana, com ênfase na Bacia do Paraná, Brasil. Universidade Federal do Rio Grande do Sul - UFRGS, Tese de Doutorado, Porto Alegre, $206 \mathrm{p}$.

FILIPIAK, P. 2005. Late Devonian and Early Carboniferous acritarchs and prasinophytes from the Holy Cross Mountains (central Poland). Review of Palaeobotany and Palynology, 134: 1-26.

GAUCHER, C.; BOGGIANI, P.C.; SPRECHMANN, P.; SIAL, A.N.; FAIRCHILD, T. 2003. Integrated correlation of the Vendian to Cambrian Arroyo del Soldado and Corumba Groups (Uruguay and Brazil) palaeogeographic, palaeoclimatic and palaeobiologic implications. Precambrian Research, 120: 241-278.

GUY-OHLSON, D. 1996. Prasinophycean algae. In: J. Jansonius \& D.C. McGregor (eds.) Palynology: Principles and Applications. Utah, American Association of Stratigraphic Palynologist Foundation, 1: 181-189.

HOLZ, M.; DIAS, M.E. 1998. Taphonomy of palynological records in a sequence stratigraphy framework: an example from the Eo-Permian from the Paraná Basin of southern Brazil. In: SBP, CONGRESSO BRASILEIRO DE PALEONTOLOGIA, 15, São Pedro, Anais, 1: 163-163.

HOLZ, M., FRANÇA, A.B., SOUZA, P.A., IANNUZZI, R.; ROHN, R. 2010. A stratigraphic chart of the Late Carboniferous/ Permian succession of the eastern border of the Paraná Basin, Brazil, South America. Journal of South American Earth Sciences, 29: 381-399.

LE HÉRISSÉ, A. 1989. Acritarches et kystes d'algues Prasinophycees du Silurien de Gotland, Suède. Palaeontographia Italica, 76: 57-302.

LE HÉRISSÉ,A.; GOURVENNEC, R.; WICANDER, R. 1997. Biogeography of late Silurian and
Devonian acritarchs and prasinophytes. Review of Palaeobotany and Palynology, 98: 105-124.

LE HÉRISSÉ, A.; SERVAIS, T.; WICANDER, R. 2000. Devonian acritarchs and related forms. Courier Forschungsinstitut Senckenberg Frankfurt, 220: 195-205.

LEI, Y.; SERVAIS, T.; FENG, Q. 2012. Permian phytoplankton diversity: a big surprise. Japanese Journal of Palynology, 58: 123.

LI, J. 1987. Ordovician acritarchs from the Meitan Formation of Guizhou Province, south-west China. Palaeontology, 30: 613-634.

LOEBLICH Jr., A.R. 1970. Morphology, ultra structure and distribution of Paleozoic acritarchs. Proceedings of the North American Paleontological Convention, part G, 2: 705-788.

MARTIN, F. 1993. Acritarchs: A review. Biological Reviews, 68: 475-538.

MAULLER, P.M. 2008. Bioestratigrafia do Devoniano da Bacia do Paraná-Brasil, com ênfase na Sub-Bacia de Alto Garças. Universidade do Estado do Rio de Janeiro, Rio de Janeiro, Tese de Doutorado, $141 \mathrm{p}$.

MEDEANIC, S. 2006. The palynomorphs from surface sediments of intertidal marshes in the estuarine part of the Patos Lagoon. Iheringia, 61(1-2): 49-62.

MELO, J.H.G. 1988. The Malvinokaffric Realm in the Devonian of Brazil. In: N. J. McMillan, A.F. Embry \& D.J. Glass (eds.) Devonian of the World. Canadian Society of Petroleum Geologists, Memoir, 14: 669-703.

MOCZYDEOWSKA, M. 1991. Acritarch biostratigraphy of the Lower Cambrian and the Precambrian-Cambrian boundary in southeastern Poland. Fossils and Strata, 29, $127 \mathrm{p}$.

MOLDOWAN, J.M.; DAHL, J.; JACOBSON, S.R.; HUIZINGA, B.J.; FAGO, F.J.; SHETTY, R.; WATT, D.S.; PETERS, K.E. 1996. Chemostratigraphic reconstruction of biofacies: molecular evidence linking cyst forming dinoflagellates with pre-Triassic ancestors. Geology, 24(2): 159-162.

MOLYNEUX, S.G.; MANGER, W.; OWENS, B. 1984. Preliminary account of Late 
Devonian palynomorph assemblages from the Bedford Shale and Berea Sandstone Formations of central Ohio, U.S.A. Journal of Micropalaeontology, 3(2): 41-51.

MOLYNEUX, S.G.;LEHÉRISSÉ,A.; WICANDER, R. 1996. Palaeozoic Phytoplankton. In: J. Jansonius, D.C. McGregor (eds.) Palynology: Principles and Applications. Utah, American Association of Stratigraphic Palynologist Foundation, v.2: 493-529.

MONTENARI, M.; LEPPIG, U. 2003. The Acritarcha: their classification morphology, ultrastructure and palaeoecological/palaeogeographical distribution. Paläontologische Zeitschrift, 77: 173-194.

NEWTON, E.T. 1875. On "Tasmanite" and Australian "White coal". Geological Magazine, 2: 337-342.

OLIVEIRA, S.F. 1991. Acritarcas e prasinófitas da Formação Ponta Grossa (Devoniano) no flanco noroeste da Bacia do Paraná. Instituto de Geociências, Universidade de São Paulo, São Paulo, Dissertação de Mestrado, 157 p.

OLIVEIRA, S.F. 1997. Palinologia da sequência Devoniana da Bacia do Paraná no Brasil, Paraguai e Uruguai: Implicações biocronoestratigráficas, paleoambientais e paleogeográficas. Instituto de Geociências, Universidade de São Paulo, São Paulo, Tese de Doutorado, 232 p.

PARIS, F.; LE HÉRISSÉ, A.; MONOD, O.; KOZLU, H.; GHIENNE, J.F.; DEAN, W.T.; VECOLI, M.; GÜNAY, Y. 2007. Ordovician chitinozoans and acritarchs from southern and southeastern Turkey. Revue de Micropaléontologie, 50(1): 81-107.

PEREIRA, Z. 2004. Glossário de Palinologia: banco de dados mantido pela INETI/e-Geo (Sistema Nacional de Informação Científica). Disponível em: http://e-geo.ineti.pt/bds/ palinologia/ default.htm.

PLAYFORD, G. 2003. Acritarchs and prasinophyte phycomata: a short course. American Association of Stratigraphic Palynologists Contributions Series, 41: 1-39.

QUADROS, L.P. 1982. Distribuição bioestratigráfica dos Chitinozoa e Acritarchae na Bacia do Parnaíba. Petrobrás - SINTEP, 12: 1-76.
QUADROS, L.P. 1985. Natureza do contato entre as formações Trombetas e Maecuru (Bacia do Amazonas). DNPM (Série Geologia), 27: 435-441.

QUADROS, L.P. 1986. Ocorrências de Microfósseis (Acritarchae) Ordovicianos na sub-bacia do Alto Amazonas, Brasil. Boletim Técnico da Petrobrás, 29(3): 181-191.

QUADROS, L.P. 1999. Silurian-Devonian acritarch assemblages from Parana Basin: an update and correlation with northern Brazilian basins. In: M.A.C Rodrigues \& E. Pereira (eds.) Ordovician-Devonian Palynostratigraphy in Western Gondwana: Update, Problems and Perspectives. Rio de Janeiro, UERJ, 1: 105-145.

RAEVSKAYA, E.; GOLUBKOVA, E. 2006. Biostratigraphical implication of MiddleUpper Cambrian acritarchs from Severnaya Zemlya (high Arctic Russia). Review of Palaeobotany and Palynology, 139: 53-69.

RAEVSKAYA, E.G. ; SERVAIS, T. 2009. Ninadiacrodium: A new Late Cambrian acritarch genus and index fossil. Palynology, 33(1): 219-239.

RICHARDSON, J.B.; RASUL, M. ; AL-AMERI, T. 1981. Acritarchs, miospores and correlation of the Ludlowian-Downtonian and SilurianDevonian boundaries. Review of Palaeobotany and Palynology, 34: 209-224.

RIEGEL, W. 2008. The Late Palaeozoic phytoplankton blackout - Artefact or evidence of global change? Review of Palaeobotany and Palynology, 148(2-4): 73-90.

RUBINSTEIN, C.V. 1995. Acritarchs from the Upper Silurian of Argentina: Their relationship with Gondwana. Journal of South American Earth Sciences, 8(1): 103-115.

RUBINSTEIN, C.V. 2000. Middle Devonian palynomorphs from the San Juan Precordillera, Argentina: Biostratigraphy and Paleobiogeography. In: I Congresso Ibérico de Paleontologia / XVI Jornadas de la Sociedad Española de Paleontología / VIII International Meeting of IGCP 421, Evora, Anais, pp. 274-275.

RUBINSTEIN, C.V.; BRUSSA, E.D. 1999. A palynomorph and graptolite biostratigraphy 
of the Central Precordillera Silurian Basin, Argentina. Bollettino della Società Paleontologica Italiana, 38(2-3): 257-266.

RUBINSTEIN, C.V.; LA PUENTE, G.S. 2008. Bioestratigrafía del Paleozoico inferior en las Sierras Subandinas, Provincia de Jujuy. In: B. Coira \& E.O. Zappettini (Eds.) XVII Congreso Geológico Argentino. Geología y Recursos Naturales de Jujuy, Relatorio, p. 128-133.

RUBINSTEIN, C.V.; LE HÉRISSÉ,A.; STEEMANS, P. 2008. Lochkovian (Early Devonian) acritarchs and prasinophytes from the Solimões Basin, northwestern Brazil. Neues Jahrbuch für Geologie und Paläontologie Abhandlungen, 249(2): 167-184.

SARJEANT, W.A.S. 1967. Observations on the acritarch genus Micrhystridium (Deflandre). Revue de Micropaléontologie, 9(4): 201-208.

SARJEANT, W.A.S.; STANCLIFFE, R.P.W. 1994. The Micrhystridium and Veryhachium complexes (Acritarcha: Acanthomorphitae and Polygonomorphitae): a taxonomic reconsideration. Micropaleontology, 40(1): 1 -77 .

SCHWARK, L.; EMPT, P. 2002. Paleozoic algal evolution reflected in steroid biomarker composition. GEO. Progr. \& Kurzf., p. 309.

SERVAIS, T.; NÜTZEL, A.; MULLINS, G. 2006. Was there a phytoplankton blackout in the Late Paleozoic? American Association of Stratigraphic Palynologists Newsletter, 39(1): 13-14.

SIMONETTI, C.; FAIRCHILD, T.R. 2000. Proterozoic microfossils from subsurface siliciclastic rocks of the São Francisco Craton, south-central Brazil. Precambrian Research, 103(1): 1-29.

SOUZA, P.A.; PETRI, S. 1998. Reworked palynomorphs in the Upper Carboniferous sediments at Araçoiaba da Serra (Itararé Subgroup, Paraná Basin), State of São Paulo, Brazil. Ameghiniana, 35(4): 379-385.

SOUZA, P.A.; PETRI, S.; DINO, R. 2003. Late Carboniferous palynology from the Itarare Subgroup (Paraná Basin) at Araçoiaba da Serra, São Paulo State, Brazil. Palynology, 27: 39-74.
STAPLIN, F.L. 1961. Reef-controlled distribution of Devonian microplankton in Alberta. Palaeontologie, 4(3): 392-424.

STROTHER, P.K. 1994. Sedimentation of palynomorphs in rocks of pre- Devonian age. In: A. Traverse (ed.) Sedimentation of organic particles. Cambridge, Cambridge University Press, p. 489-502.

STROTHER, P.K. 1996. Acritarchs. In: J. Jansonius \& D.C. McGregor (Eds.) Palynology: Principles and Applications. Utah, American Association of Stratigraphic Palynologists Foundation, v.1: 81-106.

STROTHER, P.K. 2008. A speculative review of factors controlling the evolution of phytoplankton during Paleozoic time. Revue de Micropaléontolgie, 51: 9-21.

TAPPAN, H. 1980. The Paleobiology of Plant Protists. W.H. Freeman and Company, San Francisco, USA, $1028 \mathrm{p}$.

TAPPAN, H.; LOEBLICH, A.R. 1973. Evolution of the oceanic plankton. Earth-Science Reviews, 9: 207-240.

TONGIORGI, M.; LEIMING, Y.; DI MILIA, A. 1995. Arenigian acritarchs from the Daping Section (Yangtze Gorges area, Hubei province, southern China) and their palaeogeographic significance. Review of Palaeobotany and Palynology, 86: 13-48.

TRAVERSE, A. 2008. Paleopalynology. Springer, Dordrecht, USA, $813 \mathrm{p}$.

TURNER, R.E. 1984. Acritarchs from the type area of the Ordovician Caradoc Series, Shropshire, England. Palaeontographica B, 190: 87-157.

VANGUESTAINE, M. 1986. Late Devonian and Carboniferous acritarch stratigraphy and paleogeography. Annales de la Société Géologique de Belgique, 109: 93-102.

VAVRDOVÁ, M. 1974. Geographical differentiation of Ordovician acritarch assemblages in Europe. Review of Palaeobotany and Palynology, 18: 171-175.

VAVRDOVÁ, M.; ISAACSON, P.E. 1999. Late Famennian phytogeographic provincialism: 
evidence for a limited separation of Gondwana and Laurentia. In: R. Feist, J.A. Talent, A. Daurer (eds.) North Gondwana: MidPaleozoic Terranes, Stratigraphy and Biota. Viena, Abhandlungen der Geologischen Bundesanstalt, 54: 453-463.

VECOLI, M. 1996. Stratigraphic significance of acritarchs in Cambro-Ordovician strata, Hassi-Rmel area, Algerian Sahara. Bollettino della Società Paleontologica Italiana 35: 3-58.

WALL, D. 1965. Microplankton, pollen and spores from de Lower Jurassic in Britain. Micropaleontology, 11(2): 151-190.

WETZEL, O. 1933. Die in organischer Substanz erhaltenen Mikrofossilien des baltischen Kreide-Feuersteins mit einem sedimentpetrographischen und stratigraphischen Anhang. Palaeontographica Abt. A, 78: 1-110.

WICANDER, R. 1975. Fluctuations in a Late Devonian-Early Mississippian phytoplankton flora of Ohio. Palaeogeography, Palaeoclimatology, Palaeoecology, 17: 89-108.

WILLIAMS, D.B.; SARJEANT, W.A.S. 1967. Organic-walled microfossils as depth and shoreline indicators. Marine Geology, 5: 389-412.

WINSLOW, M. 1962. Plant spores and other microfossils from the Upper Devonian and Lower Mississippian rocks of Ohio. Geological Survey Professional Paper Journal, 364: 1-89.

\section{Endereço dos autores:}

Cristina Moreira Félix e Paulo Alves de Souza - Laboratório de Palinologia Marleni Marques Toigo, Instituto de Geociências, Universidade Federal do Rio Grande do Sul, Av. Bento Gonçalves, 9500, CEP 91.540000, Porto Alegre, RS, Brasil.E-mails: cmfelixrs@yahoo.com.br, paulo.alves.souza@ufrgs.br 